\title{
Pola Distribusi Keong Air Tawar Melanoides Tuberculata (Muller, 1774) Di Danau Lindu, Sigi, Sulawesi Tengah
}

\section{(Distribution Patterns Freshwater Snail Melanoides Tuberculata (Muller, 1774) In Lindu Lake, Sigi, Central Sulawesi)}

\author{
Mohamad Basit ${ }^{1 *}$ dan Annawaty ${ }^{1}$ \\ 1 Jurusan Biologi, Fakultas MIPA Universitas Tadulako JI. Soekarno Hatta km 9 Tondo, Palu 94117, Sulawesi Tengah, \\ Indonesia.
}

Keywords: Melanoides tuberculata, distribution patterns, Lake Lindu, Central Sulawesi

Keywords: Melanoides tuberculata, Pola distribusi, Danau Lindu, Sulawesi Tengah

* Coresponding Author : moh.basit97@gmail.com

\begin{abstract}
This research was carried out in the littoral zone of Lake Lindu, Sigi Regency, Central Sulawesi with the aim to determine the distribution pattern of freshwater snail Melanoides tuberculata (Muller, 1774) whose area was divided into 5 sample sampling stations. Collecting samples using the transect line method drawn from the edge of the lake to the middle part of the $17 \mathrm{~m}$ long lake. Lines at each station are placed with a $19 \times 15 \mathrm{~cm}$ reducing plot whose size is in accordance with the collection tool. The equipment for which the plot is placed is spaced $1.5 \mathrm{~m}$, with the transect line collected three and having a distance of $2 \mathrm{~m}$. Melanoides tuberculata (Muller, 1774) which is located in Lake Lindu, Sigi, Central Sulawesi, is distributed randomly and in groups.
\end{abstract}

\begin{abstract}
Abstrak
Penelitian ini dilakukan di zona littoral Danau Lindu, Kabupaten Sigi, Sulawesi Tengah dengan tujuan untuk mengetahui pola distribusi keong air tawar Melanoides tuberculata (Muller, 1774) yang wilayahnya dibagi kedalam 5 stasiun pengambian sampel. Pengoleksian sampel menggunakan metode garis transek yang ditarik dari tepi danau hinggga ke bagian tengah danau sepanjang $17 \mathrm{~m}$. Garis di setiap stasiun di tempatkan plot memotong berukuran $19 \times 15 \mathrm{~cm}$ yang ukurannya sesuai dengan alat koleksi Equipment grab yang penempatan plotnya diberi jarak 1,5 m, dengan garis transek berjumlah tiga dan memiliki jarak $2 \mathrm{~m}$. Pada penelitian ini menunjukan hasil bahwa, keong air tawar jenis Melanoides tuberculata (Muller, 1774) yang berada di Danau Lindu, Sigi, Sulawesi Tengah terdistribusi secara acak dan berkelompok.
\end{abstract}

\section{Latar Belakang}

Danau Lindu merupakan danau yang berada di Kecamatan Lindu, Kabupaten Sigi, Sulawesi Tengah, Indonesia. Danau yang sebagian wilayahnya termasuk ke dalam lokasi Taman Nasional Lore Lindu ini terletak di ketinggian $1.000 \mathrm{~m}$ di atas permukaan laut dan memiliki kedalaman maksimum 72,6 m (Lukman, 2007).
Danau Lindu memiliki tingkat endemisitas fauna yang tinggi. Beberapa fauna endemik danau ini yaitu ikan Xenopoechilus sarasinorum dan beberapa anggota filum Mollusca kelas Bivalvia seperti Corbicula lindoensis dan C. sublanata (Anthony dkk., 1991). Selain anggota dari filum Mollusca kelas Bivalvia di sekitar wilayah danau ini terdapat juga keong Oncomelania hupensis lindoensis yang merupakan keong air tawar dari kelas Gastropoda 
dan menjadi inang perantara cacing Schistosoma. Cacing ini dapat menyebabkan penyakit demam keong atau dikenal dengan nama penyakit Schistosomiasis. Jenis keong $O$. hupensis lindoensis memiliki ukuran yang kecil, dan menyukai habitat dengan kandungan air yang tinggi, baik di limpasan sungai maupun rembesan dari tepi hutan yang bervegetasi atau banyak tumpukan serasah, kayu lapuk dan tidak berada di wilayah perairan (Lukman, 2007).

Banyaknya studi mengenai filum Mollusca kelas Gastropoda Oncomelania hupensis lindoensis tidak sebanding dengan kajian mengenai Mollusca lainnya, terutama yang hidup di danau, termasuk pola distribusinya, karena itu penelitian ini bertujuan untuk mengetahui pola distribusi salah satu keong air tawar yang terdapat di Danau Lindu yaitu Melanoides tuberculata (Muller, 1774).

\section{Bahan dan Metode}

Penelitian dilakukan di zona littoral Danau Lindu pada bulan Februai 2019. Lokasi penelitian dibagi menjadi 5 stasiun yang ditunjukan pada tabel 1 .

Koleksi sampel menggunakan metode garis transek yang ditarik dari tepi danau hingga ke arah tengah danau sepanjang $17 \mathrm{~m}$ lalu ditempatkan plot memotong dengan besaran $15 \times 19 \mathrm{~cm}$ yang disesuaikan dengan ukuran dari alat pengambilan sampel yaitu equipment grab (Marwoto dan Djajasasmita 1986). Sampel yang diperoleh kemudian direlaksasi menggunakan Magnesium Sulfat dan difiksasi menggunakan alkohol $96 \%$. Selanjutnya dipreservasi ke dalam botol yang berisi alkohol $96 \%$.

Koleksi sampel pada penelitian ini diawali dengan pengukuran parameter lingkungan yang meliputi suhu, derajat keasaman $(\mathrm{pH})$ oksigen terlarut, kekeruhan, dan substrat (Tabel 2).

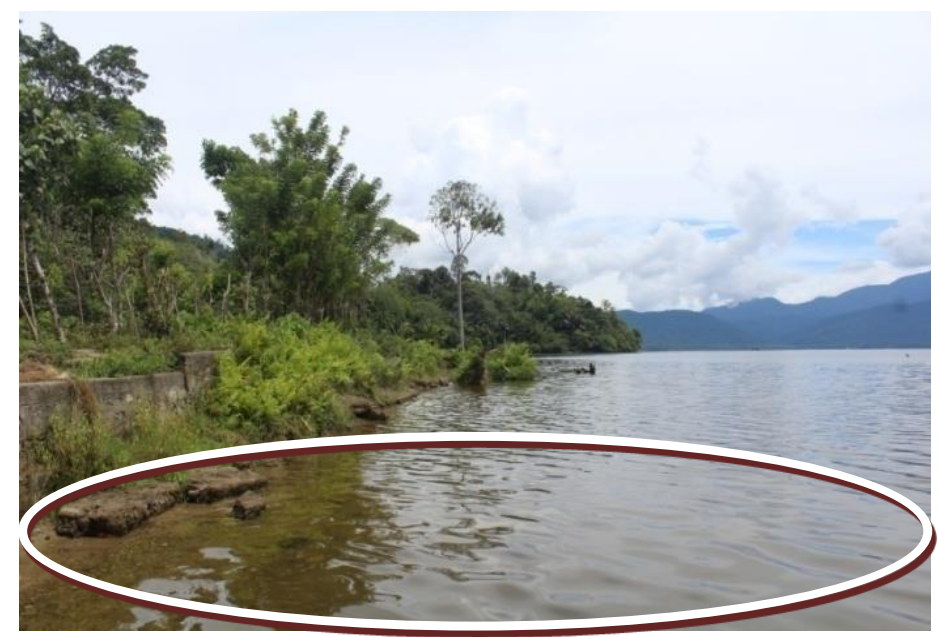

Gambar 1. Zona littoral Danau Lindu dengan wilayah pengambilan sampel yang diberi lingkaran merah

Tabel 1. Lokasi pengambilan sampel keong air tawar Melanoides tuberculata (Muller, 1774)

\begin{tabular}{|c|c|c|c|}
\hline Stasiun & \multicolumn{2}{|c|}{ Koordinat } & Ketinggian \\
\hline 1 & S $01^{\circ} 19^{\prime} 33,7^{\prime \prime}$ & E 12003'08,9" & $977 \mathrm{mdpl}$ \\
\hline 2 & S $01^{\circ} 20^{\prime} 47,6^{\prime \prime}$ & E $120^{\circ} 04^{\prime} 02,6^{\prime \prime}$ & 978 mdpl \\
\hline 3 & S $01^{\circ} 19^{\prime} 13,4^{\prime \prime}$ & E $120^{\circ} 06^{\prime} 15,5^{\prime \prime}$ & 975 mdpl \\
\hline 4 & S $01^{\circ} 17^{\prime} 30,0^{\prime \prime}$ & E $120^{\circ} 06^{\prime} 27,8^{\prime \prime}$ & 969 mdpl \\
\hline 5 & S 0118'57,8" & E $120^{\circ} 03^{\prime} 27,1^{\prime \prime}$ & 980 mdpl \\
\hline
\end{tabular}

Keterangan: Stasiun 3 dan 4 berada pada lokasi desa yang sama namun titik pengambilan berbeda

Tabel 2. Pengukuran parameter lingkungan

\begin{tabular}{cccccc}
\hline \multirow{2}{*}{ Stasiun } & \multicolumn{5}{c}{ Parameter lingkungan } \\
\cline { 2 - 6 } & Suhu $\left({ }^{\circ} \mathrm{C}\right)$ & $\begin{array}{c}\text { Derajat keasaman } \\
(\mathrm{pH})\end{array}$ & $\begin{array}{c}\text { Oksigen } \\
\text { terlarut } \mathrm{mg} / \mathrm{l}\end{array}$ & $\begin{array}{c}\text { Kecerahan } \\
(\mathrm{m})\end{array}$ & Substrat \\
\hline 1 & 30 & 9,2 & 7,6 & 1,52 & Pasir dan Pasir berlumpur \\
2 & 26 & 9,5 & 6,8 & 1,23 & Pasir dan Pasir berlumpur \\
3 & 29 & 9,8 & 7,4 & 1 & Pasir dan Pasir berlumpur \\
4 & 28 & 8,3 & 5,6 & 1 & Pasir dan Pasir berlumpur \\
5 & 29 & 9,9 & 7,1 & 2 & Pasir dan Pasir berlumpur \\
\hline \multicolumn{4}{r}{ Keterangan: pengukuran parameter lingkungan dilakukan disetiap stasiun dengan satu kali pengulangan }
\end{tabular}




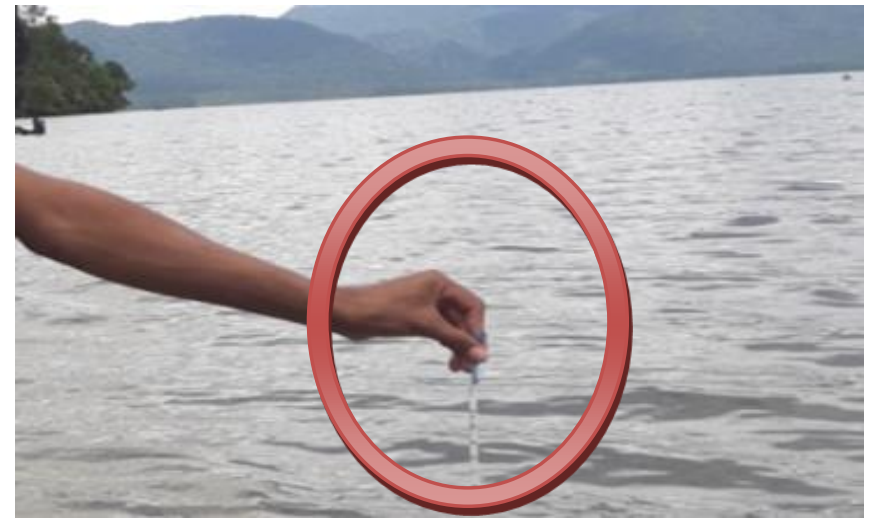

Gambar 2. Pengukuran suhu menggunakan thermometer yang diberi lingkaran merah.

Identifikasi dan pengukuran morfometri dilakukan di Laboratoriuum Biosistematika Hewan dan Evolusi Jurusan Biologi FMIPA Universitas Tadulako yang mengacu pada Heryanto dkk. (2003), Jutting (1956) dan Djajasasmita (1999). Spesimen yang telah diidentifiikasi selanjutnya disimpan sebagai spesimen koleksi Laboratorium Biosistematika Hewan dan Evolusi Jurusan Biologi FMIPA Universitas Tadulako. Selanjutnya dilakukan analisis data. Menurut Krebs (1978) indeks sebaran dapat diformulasikan sebagai berikut:

$$
\mathrm{Id}=\frac{\sum \mathrm{ni}(\mathrm{ni}-1) \mathrm{N}}{\mathrm{n}(\mathrm{ni}-1)}
$$

Dimana:

Id : indeks sebaran morisita

$\mathrm{Ni}$ : jumlah individu padakuadrat pengambilan

q : : jumlah kuadrat pengambilan

$\mathrm{N} \quad$ : jumlah total pengambilan

Dengan kriteria sebagai berikut:

Id $=1$ pola distribusi bersifat acak

Id $>1$ pola distribusi bersifat kelompok

Id $<1$ pola distribusi bersifat teratur

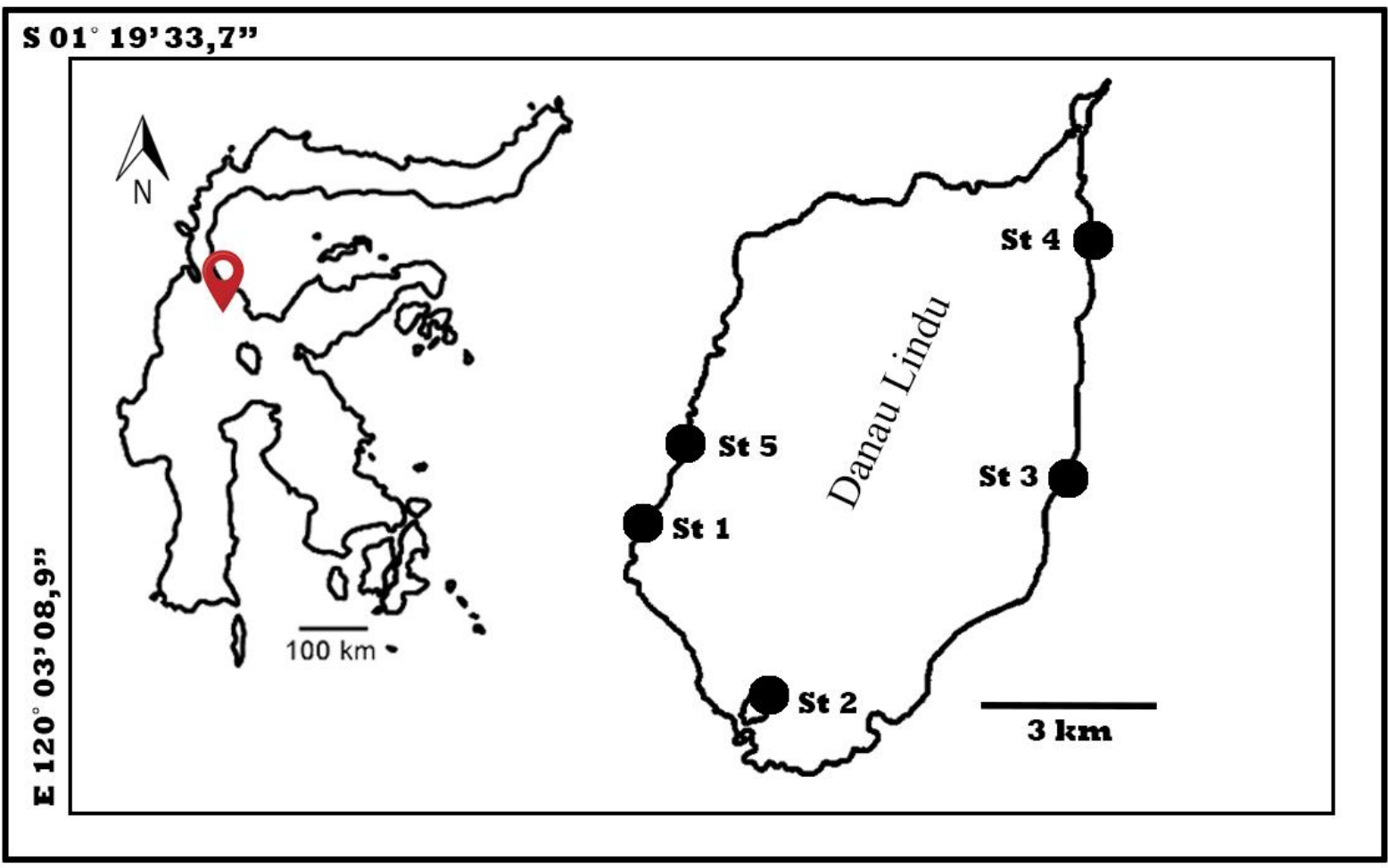

Gambar 3. Lokasi pengoleksian keong air tawar Melanoides tuberculata (Muller 1774) St 1 Desa Tomado, St 2 Pulau Bola, St 3 Desa Olu, St 4Desa Olu, Dusun Palili, St 5 Desa Anca

\section{Hasil dan Pembahasan}

Keong air tawar Melanoides tuberculata (Muller, 1774) yang ditemukan di Danau Lindu adalah salah satu jenis keong yang berasal dari famili Thiaridae. Keong air tawar famili Thiaridae menyukai habitat dengan dasar perairan berlumpur dan berpasir. Hal ini sesuai dengan habitat tempat ditemukannya keong ini di Danau Lindu, yaitu ditemukan pada habitat perairan dengan dasar berpasir dan berlumpur (Djajasasmita 1999). 
Selain substrat, suhu yang berkisar antar $26^{\circ} \mathrm{C}-30^{\circ} \mathrm{C}$ dan kandungan oksigen terlarut yang berkisar antara 5,6-7,6 mg/l nampaknya masih tergolong baik bagi kelangsungan hidup keong air tawar $M$. tuberculata. Menurut Palmieri et al., (1980) kisaran suhu yang memungkinkan Molllusca hidup di suatu perairan yaitu $26^{\circ} \mathrm{C}-32^{\circ} \mathrm{C}$ dan oksigen terlarut berkisar antara $1-13$ $\mathrm{mg} / \mathrm{l}$.

Keong air tawar jenis Melanoides tuberculata (Muller, 1774) yang ditemukan di Danau Lindu, Kabupaten Sigi, Sulawesi Tengah berjumlah 172 individu. Berdasarkan hasil analisa, keong air tawar $M$. tuberculata terdistribusi secara acak dan berkelompok yang ditunjukan pada Tabel 3.

Tabel 3. Jumlah dan Pola distribusi keong Melanoides tuberculata (Muller, 1774) dari Danau Lindu

\begin{tabular}{ccc}
\hline \multirow{2}{*}{ Stasiun } & \multicolumn{2}{c}{ Melanoides tuberculata (Muller, 1774) } \\
\cline { 2 - 3 } & Jumlah & Pola distribusi \\
\hline 1 & 41 & Kelompok \\
2 & 37 & Acak \\
3 & 29 & Acak \\
4 & 64 & Kelompok \\
5 & 1 & Kelompok
\end{tabular}

Keterangan: Pola distribusi keong Melanoides tuberculata (Muller, 1774) di stasiun 1,4 dan 5 memiliki pola yang bersifat kelompok sedangkan di stasiun 2 dan 3 memiliki pola yang bersifat acak.

Hasil analisa yang menunjukan pola distribusi Melanoides tuberculata (Muller, 1774) yang ditemukan dengan sifat distribusi yang berkelompok menurut Marwoto dan Djajasasmita (1986) karena kebiasaan makan dan terdapat kecenderungan yang kuat untuk bersaing dengan biota lain terutama dalam hal makan. Hal ini dapat dilihat dari ukuran cangkang $M$. tuberculata yang ditemukan hanya berkisar antara $11,69 \mathrm{~mm}$ hingga $25,56 \mathrm{~mm}$. Sementara dalam hasil penelitian yang dilakukan Marwoto dan Djajasasmita (1986) di tepi Danau Singkarak, Sumatera Barat menyatakan bahwa ukuran normal dari $M$. tuberculata dapat mencapai $30 \mathrm{~mm}$. Keong air tawar jenis $M$. tuberculata juga pernah ditemukan dengan sifat pola distribusi secara berkelompok di Danau Diatas, Kabupaten Solok, Provinsi Sumatera Barat (Mardatalia, 2016), dan di Waduk Saguling dan sekitarnya (Wahyono, 2005). Selanjutnya menurut Mardatila dkk. (2016) pola distribusi secara berkelompok disebabkan oleh cara bereproduksi, tipe substrat, kebiasaan makan, dan kondisi lingkungan.
Selanjutnya pola distribusi keong air tawar jenis Melanoides tuberculata (Muller, 1774) yang ditemukan dengan pola distribusi yag bersifat acak diduga akibat kondisi dasar perairan yang tercemar oleh sampah anorganik dari tepi Danau Lindu seperti yang ditunjukan pada Gambar 4

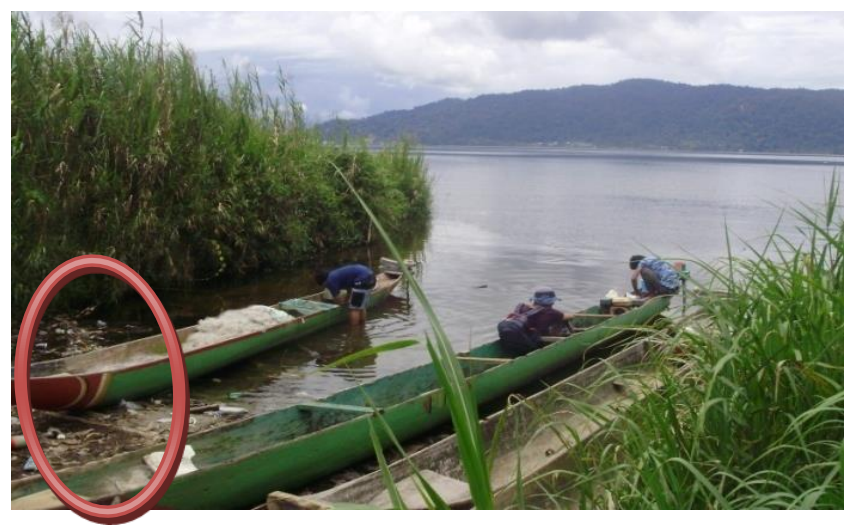

Gambar 4. lokasi pengambilan sampel dengan wilayah yang dilingkar merah merupakan sampah yang berada di daerah tepi danau

Pengaruh sampah yang terbawa arus dan tenggelam ke dasar perairan diduga dapat menyebabkan makanan keong yang tidak merata karena material anorganik yang diduga tidak mampu terdekomposisi oleh keong air tawar. Jonasson (1978) menyatakan Gastropoda berperan penting dalam dekomposisi yang berupa material organik secara mekanis melalui aktivitas makannya.

Selain itu, Fried and Hademenos (1999) menyatakan bahwa penyebaran suatu organisme ditentukan sifat pola distribusinya yang dipengaruhi oleh sifat biotik dan abiotik lingkungan, ketersediaan sumber daya, tingkat sosialisasi organisme dalam suatu populasi, dan interaksi dengan dengan spesies lain.

Menurut Djajasasmita (1999) keong air tawar Melanoides tuberculata (Muller, 1774) terdistribusi di Eropa Selatan, Afrika, Asia, Australia, Myanmar dan Pasifik Barat. Di Indonesia keong ini ditemukan di Tangerang Selatan yaitu di Danau Situ Gintung (Assuyuti dkk.,2017), di Waduk Saguling dan sekitarnya (Wahyono, 2005), di tepi Danau Singkarak (Marwoto dan Djajasmita, 1986) dan pernah ditemukan di Danau Diatas, Kabupaten Solok, Sumatera Barat (Mardatila dkk., 2016).

Melanoides tuberculata (Muller, 1774) memiliki karakter yaitu cangkang berukuran sedang, putaran cangkang ke arah kanan (dextral), cangkang berbentuk gulungan benang, terdapat garis axial pada daerah puncak 
menara (spire), terdapat pola seperti nyala api yang tersebar secara acak atau teratur seperti garis axial di seluruh permukaan cangkang, jenis pusar (umbilicus) tertutup, dan mulut cangkang (aperture) berbentuk lonjong.

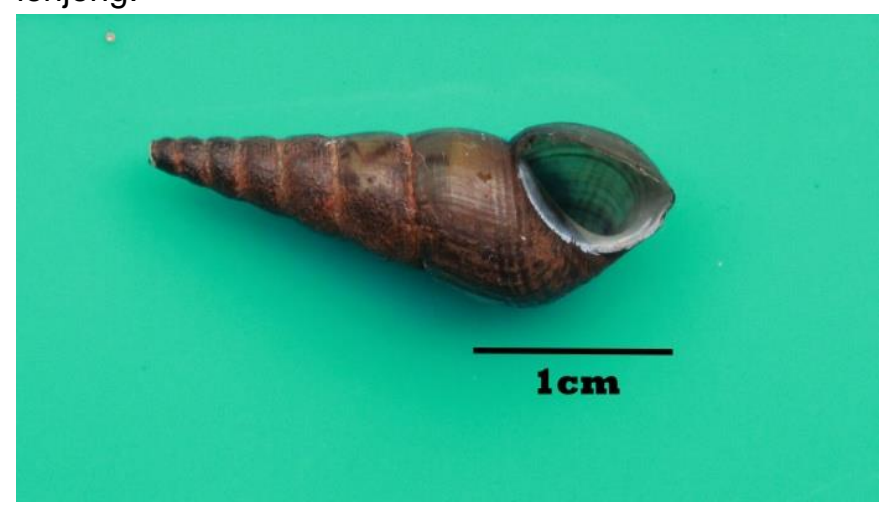

Gambar 5. Morfologi cangkang Melanoides tuberculata (Muller, 1774)

Keong Oncomelania hupensis linduensi yang dapat menjadi vektor perantara cacing Schistosoma, juga memiliki potensi yang sama seperti keong air tawar jenis Melanoides tuberculata (Muller, 1774) yaitu bersifat sebagai vektor. Menurut Djajasasmita (1999) M. tuberculata (Muller, 1774) berpotensi sebagai vektor perantara cacing Trematoda parasit Paragonimus westermani yang dapat menyebabkan penyakit radang paru-paru. Meskipun dalam penelitian Annida dan Paisal, (2014) tidak menemukan cacing Trematoda pada keong air tawar dari genus Melanoides yang dilakukan di Desa Kalumpang Dalam dan Sungai Papuyu, Kecamatan Babirik, Kabupaten Hulu Sungai Utara. Hal ini diduga keong air tawar dari genus Melanoides hanya dapat menjadi inang cacing Trematoda tertentu dengan jenis tertentu.

\section{Ucapan Terima Kasih}

Terima kasih kepada Ibu Ir. Ristiyanti M. Marwoto M.Si dan Bapak Ir. Heryanto M.Sc atas bimbingannya dalam proses identifikasi sampel. Kepada Irfan Tasman S.Si, Evan Madiyono S.Si, Aswandi S.Si, Jason Thomas Karuntu, dan Steven S. Ladado yang telah membantu dalam proses pengambilan sampel di lapangan.

\section{DAFTAR PUSTAKA}

Anthony, W. J., dan Kartawinata, K. (1991). Krisis Biologi Hilangnya Keanekaragaman Biologi. Jamthani, $\quad H$. , Soeyanti., Suherly, L. (penerjemah); Jakarta: Yayasan Obor Indonesia.

Annida dan Paisal. (2014). Siput air tawar sebagai Hospes perantara Trematoda di Desa Kalumpang Dalam dan Sungai Papuyu, Kecamatan Babirik, Kabupaten Hulu Sungai Utara. Jurnal Buski. 5(2): 55-60

Assuyuti, M. Y., Rijaluddin, F.A., Ramadhan, F., Zikrillah, B., R., Kusuma, C., D., (2017). Struktur Komunitas dan Distribusi Gastropoda di Danau Situ Gintung, Tanggerang Selatan, Banten. Scripta Biologica. 4(3): 139-156.

Djajasasmita M. (1999) Keong dan Kerang Sawah (LIPI-Seri Panduan Lapangan) Puslitbang Biologi LIPI. Bogor.

Fried, H. G. and G. J. Hademenos. (1999) Schaum'sOutline of Theory and Problems of Biology. Second Edition. Jakarta. Erlangga.

Lukman. (2007). Danau Lindu Keteduhan Yang Merindu. Seri 1. Jakarta. LIPI press.

Marwoto, R. M. dan Djajasasmita M. (1986). Fauna Mollusca di Perairan Tepi Danau Singkarak Sumatera Barat: Komposisis dan Kepadatan Jenisnya. Berita Biologi. 3. Balitbang Zoologi. Puslitbang Biologi-LIPI. Bogor.

Heryanto, Ristiyanti, M. M., Munandar, A. P., dan Susilowati. (2003). Keong dari Taman Nasional Gunung Halimun (sebuah buku panduan lapangan). Biodiversity Conservation Project. LIPI. Cibinong.

Jutting, V. B. W. S. S., (1956) Systematic Studies on The non-marine Mollusca of The Indo Australian Archipelago. Trubia 28 (2): 25947

Krebs, C. J. (1978) Ecological Metheodology. New York. Harper and Row Publisher. 678 p.

Mardatila, S., Izmiarti., Nurdin, J. (2016). Kepadatan, Keanekaragaman dan Pola Distribusi Gastropoda di Danau Diatas, Kabupaten Solok, Provinsi Sumatera Barat. Biocelebes: 25-31.

Palmieri, M., Palmieri, J., Sullivan, J. (1980) A Chemical Analysis of the Habitat of Nine Commonly Occuring Malaysia Freshwater Snails. The Malayan Nature Journal 34 (1): 39-45.

Wahyono, S. (2005) Identifikasi Populasi Gastropoda air tawar di Waduk Saguling dan sekitarnya. Tek.Ling. PBTL-BPPT. 6 (1): 274-282. 